\title{
Markers of accessory glands and seminal parameters in infertile men with overweight and obesity
}

\author{
Ricardo Lozano-Hernández ${ }^{1}$, Javier Gualdrón ${ }^{1}$, María I Camejo ${ }^{2(\dagger)}$, Velasco Judith ${ }^{1}$ and Villavicencio Antonio ${ }^{1}$ \\ ${ }^{1}$ Center for Infertility and Gynecological Diseases (CEDIEG) Dr. Giovanny Vivas-Acevedo, University of Los Andes, Merida, Venezuela \\ ${ }^{2}$ Department of Biology of Organisms, Simón Bolivar University, Caracas, Venezuela
}

"Corresponding author: Ricardo Lozano-Hernández, Center for Infertility and Gynecological Diseases (CEDIEG) Dr. Giovanny Vivas-Acevedo, University of Los Andes, Merida, Venezuela, Tel: 584120775139; E-mail: ricardolozanoh@hotmail.com

Received date: July 24, 2017; Accepted date: August 01, 2017; Published date: August 08, 2017

Copyright: (c) 2017 Lozano-Hernández R, et al. This is an open-access article distributed under the terms of the creative commons attribution license, which permits unrestricted use, distribution, and reproduction in any medium, provided the original author and source are credited.

\begin{abstract}
Introduction: Several studies have investigated the impact of male obesity on the traditional sperm parameters but it is unclear if in the male obesity, accessory glands secretory function may be altered. In this paper the seminal parameters and the biochemical markers of accessory sex glands are related with the Body Mass Index (BMI).

Material and methods: 1148 patients attending a Fertility Center with subfertility were included in the study. Weight and height were recorded to calculate BMI in each patient. Semen parameters and markers of male accessory glands were measured. Pearson's correlation coefficient has been performed, $p$-values below 0.01 were considered statistically significant.

Results: In HOS tests a reduction was observed in I and II-III obesity groups, sperm /ejaculate number, seminal volume and citric acid decrease were correlated inversely with the body mass index. Seminal fructose levels tend to increase in proportion to body mass. The correlation analysis in all the individuals indicates a trend for increase in BMI over time.

Conclusion: Obesity has a negative impact on sperm quality and prostatic function, although sperm parameters changes are more evident in men with morbid obesity. Oxidative stress, hormonal and metabolic changes increase as adiposity progresses in an individual, so we may expect infertility, prostate pathologies could be avoided if hyperadiposity in infertile men is controlled opportunely.
\end{abstract}

Keywords: Male accessory glands; Fructose; Citric acid; Neutral alpha -glucosidase, Obesity

\section{Introduction}

The impact of body weight on reproductive health has been more studied in women than in men. Obesity can be conditioned by lifestyle and also has been considered a cause of infertility. Obesity in women can also increase risk of miscarriages and impair the outcomes of assisted reproductive technologies and pregnancy. These adverse effects are specifically evident in polycystic ovary syndrome. In men, obesity is associated with low testosterone levels. In massively obese individuals, reduced spermatogenesis may favour infertility. Moreover the frequency of erectile dysfunction increases with increasing body mass index [1]. Changes in lifestyle in obese men have been associated with body weight reduction and improved seminal parameters although it is difficult to determine whether seminal quality depends directly on the value of body mass or lifestyle changes [2]. The body mass index (BMI) is a simple and commonly used parameter for classifying various degrees of adiposity. It is derived from the weight of the individual in kilograms divided by the square of the height in meters $\left(\mathrm{kg} / \mathrm{m}^{2}\right)$. By the current World Health Organisation (WHO) criteria, a BMI $<18.5 \mathrm{~kg} / \mathrm{m}^{2}$ is considered underweight, $18.5-24.9 \mathrm{~kg} /$ $\mathrm{m}^{2}$ ideal weight and $25-29.9 \mathrm{~kg} / \mathrm{m}^{2}$ overweight or pre-obese. The obese category is sub-divided into classes I $\left(30-34.9 \mathrm{~kg} / \mathrm{m}^{2}\right)$, II $(35-39.9$ $\left.\mathrm{kg} / \mathrm{m}^{2}\right)$ and III $\left(\geq 40 \mathrm{~kg} / \mathrm{m}^{2}\right)$, the last two are considered morbid obesity [3].

The prevalence of obesity has risen steadily for the past 35 years and presently affects more than a third of the US population. Obesity alters the hypothalamic-pituitary-gonadal axis both centrally and peripherally, resulting in hypogonadotropic, hyperestrogenic hypogonadism. Adipose tissue-derived factors, like leptin and adipokines, regulate testosterone production and inflammation, respectively. Increased systemic inflammation results in increased reactive oxygen species and increased testicular temperature and inactivity of obese men impairs spermatogenesis [4]. There have been a number of studies on the impact of male obesity on the traditional sperm parameters, but there are many contradicting reports with regard to decrease in sperm concentration, sperm motility and normal forms. And it is currently unclear whether male obesity has an impact on sperm parameters [5].

The problem of obesity triggers several diseases such as diabetes, cardiovascular disease, fatty liver and cancer where oxidative stress is implicated in different physiopathological ways [6]. In obese men the effect of leptin on growth of prostate cancer cells is different according to the androgen sensitivity of the evaluated cells. It's possible that major mitogenic signal transduction pathways, such as, a mitogenactivated protein kinase (MAPK) pathway are involved in leptin exerting its mitogenic effects in these cell lines. Activation of mitogenic 
Citation: Lozano-Hernández R, Gualdrón J, Camejo MI, Velasco J, Villavicencio A (2017) Markers of accessory glands and seminal parameters in infertile men with overweight and obesity. J Metabolic Synd 6: 229. doi:10.4172/2167-0943.1000229

Page 2 of 4

signal transduction pathways by leptin could potentially serve as a target for future therapies of advanced stages of cancer of prostate [7], while in overweight men, other prostatic changes have been observed: increased size, calcifications, lack of echographic homogeneity and high arterial systolic blood pressure. In men with overweight, alterations in seminal vesicles and the epididymis functions, these have not been found [8]. Studies suggest that overweight or obesity can alter the structure and function of accessory glands, so that assessment of chemical markers of accessory glands could be important indicators of these alterations. Male accessory glands secrete several factors which can be measured to assess their function. In particular, citric acid, zinc, glutamyl transpeptidase and acid phosphatase may be used to evaluate prostatic function. Fructose and prostaglandins may be used to evaluate the secretory capacity of the seminal vesicles, free L-carnitine, glycerophosphocholine and neutral glucosidase may be used to evaluate the function of the epididymis [9]. The biomarkers fructose and neutral alpha-glucosidase were useful for to evaluate the impact of some microorganisms on male accessory glands. Some bacteria do not alter sperm density, motility or normal forms, but alter the epithelia of the seminal vesicles and the epididymis, reducing the values of their markers fructose and neutral alpha-glucosidase respectively, and altering other more specific parameters of sperm functionality. It is suggested to incorporate these markers into the study of infertile man [10]. In this paper the seminal parameters and the biochemical markers of accessory sex glands with the Body Mass Index in men attending a Fertility Center are related.

\section{Materials and Methods}

\section{Patients}

Every one of the analyses was performed after obtaining institutional board approval and each one of the patients gave their express consent. The study was carried out according to the guidelines established by the Helsinki Declaration for human research and outlined in the Code of Bioethics and Biosafety FONACIT [11]. A clinical cross-sectional analysis was conducted in patients for infertility evaluation at a diagnostic center CEDIEG (Dr. Giovanny VivasAcevedo Diagnostic Center for Infertility and Gynecological Diseases), Universidad de Los Andes, Mérida, Venezuela, from January 2010 to April 2017.

A total of 1148 patients with sub-fertility were included in the study. Prior to the seminal evaluation, the information necessary for the preanalysis including weight and height was recorded to calculate BMI. The patients' height and weight were measured in the same laboratory on the same day that their semen sample was obtained and processed. The patients were included in three groups: normal, pre-obesity, obesity (class I) and morbid obesity (classes II-III) in recognition of the fact that management options for dealing with obesity differ above a BMI of 35 .

\section{Semen analysis}

Semen samples were collected by masturbation after 2 to 7 days of ejaculatory abstinence. After semen liquefaction, seminal analysis and measuring were performed according to WHO 2010 criteria. Neutralglucosidase activity and fructose levels were used to evaluate the epididymis and seminal vesicles function respectively [12]. Citric acid was determined by colorimetric reaction following the guidelines of citric acid according to Lozano-Hernández and Vivas [10], the concentration was expressed in $\mathrm{mmol} /$ ejaculate as an indicator of prostatic function [13].

\section{Statistical analysis}

Statistical analysis has been performed using SPSS 10.0 statistical software for Windows (SPSS, Chicago, IL, USA). Basic descriptive statistics (mean $\pm \mathrm{SD}$ ) were calculated allotted to the following patients groups: normal, overweight, obesity (class I) and morbid obesity (classes II and III). Pearson's correlation coefficient was calculated and p-values below 0.01 were considered statistically significant.

\begin{tabular}{|l|l|l|l|}
\hline \multirow{2}{*}{ Total patients } & Patient characteristics & No Patients & $\begin{array}{l}\text { Percentage } \\
\text { (\%) }\end{array}$ \\
\hline \multirow{2}{*}{ Patients excluded } & Genito-urinary problems ${ }^{*}$ & 62 & 4.0 \\
\cline { 2 - 4 } & Azoospermy & 21 & 1.4 \\
\cline { 2 - 4 } & Post- surgery consult & 13 & 0.9 \\
\cline { 2 - 4 } & BMl less than 18.5 & 9 & 0.6 \\
\cline { 2 - 4 } & Incomplete form information & 17 & 1.1 \\
\hline Patients included & Patients that presented varicocele & 259 & 16.9 \\
\hline Total & Patients that consulted for infertility & 1148 & 75.1 \\
\hline BMI: body mass index. "Genito-urinary problems as infections, prostatitis, hydrocele, pain, torsion, bleeding, inflammation. & 1529 & $100 \%$ \\
\hline
\end{tabular}

Table 1: Male men attending an infertility clinic were invited to participate in an ongoing study of relationship of BMI and seminal parameters. Summary of the patients excluded and included in the study. 
Citation: Lozano-Hernández R, Gualdrón J, Camejo MI, Velasco J, Villavicencio A (2017) Markers of accessory glands and seminal parameters in infertile men with overweight and obesity. J Metabolic Synd 6: 229. doi:10.4172/2167-0943.1000229

Page 3 of 4

\section{Results}

Initially, 1529 men were enrolled, of whom 1148 were selected and 381 were excluded because they had seminal infections, prostatitis, hydrocele, testicular torsion, hemospermia, varicocele, azoospermia, genital tract phlogiston, $\mathrm{BMI}<18.5 \mathrm{~kg} / \mathrm{m}^{2}$ and post-surgery. Male men attending an infertility clinic at the CEDIEG were invited to participate in an ongoing study concerning the relationship of BMI and seminal parameters. Table 1 shows a summary of the patients excluded and included in the study.
The results highlight the high frequency of pre-obesity/obesity $(42.5 \%)$ in individuals cared for in the conjugal infertility consultations. This frequency is higher that China (33.8\%) and lower that U.S. rates $(65.5 \%)[14,15]$. It can be observed that in BMI values are higher in older men $(\mathrm{p}<0.01)$. The samples of men with obesity IIIII had lower seminal volume $(\mathrm{p}<0.001)$, lower sperm/ejaculate concentration $(\mathrm{p}<0.01)$, lower HOST $(\mathrm{p}<0.01)$, higher levels of fructose $(\mathrm{p}<0.01)$ and lower levels of citric acid $(\mathrm{p}<0.001)$ in seminal plasma with respect to other groups.

\begin{tabular}{|c|c|c|c|c|}
\hline \multirow[b]{2}{*}{ Patients/Semen quality parameters } & \multicolumn{4}{|c|}{ Body mass index $\left(\mathrm{kg} / \mathrm{m}^{2}\right)$} \\
\hline & $\begin{array}{l}\text { Normal } \\
18.5-24.9\end{array}$ & $\begin{array}{l}\text { Pre-obese } \\
25-29.9\end{array}$ & $\begin{array}{l}\text { Obese I } \\
30-34.9\end{array}$ & $\begin{array}{l}\text { Obese II-III } \\
\geq 35\end{array}$ \\
\hline $\mathbf{N}^{\circ}$ of patients $(\%)$ & $270(23.5)$ & $489(42.6)$ & $280(24.4)$ & $109(9.5)$ \\
\hline Age (years) & $31.9 \pm 8.9$ & $34.4 \pm 7.9^{1}$ & $34.6 \pm 8.0^{2}$ & $35.8 \pm 8.7^{2}$ \\
\hline Semen volume $(\mathrm{mL})$ & $3.2 \pm 1.6$ & $3.5 \pm 1.6$ & $3.3 \pm 1.6$ & $2.9 \pm 1.4^{3}$ \\
\hline Spermatozoa (x106/ejaculate) & $295 \pm 232$ & $290 \pm 255$ & $284 \pm 260$ & $238 \pm 211^{1,3,5}$ \\
\hline Motility (\%) & $34.0 \pm 22.0$ & $34.0 \pm 22.7$ & $31.2 \pm 21.4$ & $33.3 \pm 22.3$ \\
\hline Normal morphology (\%) & $7.9 \pm 3.6$ & $7.9 \pm 3.5$ & $7.4 \pm 3.6$ & $7.6 \pm 3.7$ \\
\hline HOST (\%) & $57.6 \pm 19.0$ & $59.4 \pm 18.5$ & $54.7 \pm 20.1^{1}$ & $55.5 \pm 19.5^{1}$ \\
\hline PMN (mL) & $0.6 \pm 1.2$ & $0.8 \pm 2.5$ & $0.8 \pm 1.9$ & $0.8 \pm 1.4$ \\
\hline Fructose ( $\mu \mathrm{mol} / \mathrm{ejaculate})$ & $47.6 \pm 41.3$ & $51.1 \pm 49.0$ & $50.0 \pm 39.3$ & $55.5 \pm 29.2^{1}$ \\
\hline Citric acid (mmol/ejaculate) & $99.2 \pm 79.7$ & $105.7 \pm 80.8$ & $111.1 \pm 85.3$ & $85.8 \pm 36.2^{2,3,5}$ \\
\hline Neutral alpha glucosidase (mUl/ejaculate) & $23.3 \pm 13.5$ & $21.9 \pm 13.5$ & $21.4 \pm 12.2$ & $19.8 \pm 14.1$ \\
\hline
\end{tabular}

Table 2: Semen quality parameters grouped according body mass index levels.

Markers of male accessory gland changes are observed mainly in the II-III obesity group (Table 2), but the correlation analysis in all the individuals indicates that there is a subtle tendency for decline in sperm/ejaculate number, seminal volume and citric acid as the body mass index increases, unlike the value of seminal fructose that tends to increase when this index increases (Table 3).

\section{Discussion}

Increase in body mass was related to age in this study group. Sperm parameters observed are consistent with some findings that conclude that up to the degree of obesity I there is no direct relationship between BMI and the main sperm characteristics [5].

These results are consistent with the review by Savini et al. (2012), they said that there are many contradicting reports with regard to sperm motility, morphology (normal forms), and it is currently unclear if male obesity has an impact on these parameters [6]. Only HOST was reduced in subjects with obesity I. HOST values have been inversely associated with levels of reactive oxygen species (ROS) in the male genital tract, since this alteration has been determined in the semen of fertile subjects with obesity [16]. Seminal volume and spermatozoa/ ejaculate were significantly reduced in men with obesity II-III. In this group citric acid levels were lowest; this fact allows presuming an association between the citrate anion and chronic oxidative stress. Citric acid has been assigned a restorative role in other tissues damaged by environmental factors, acting as a possible antiinflammatory and generating the synthesis of glycosaminoglycans [17].

Studies in prostate cancer in obese men have been complicated by the fact that obesity is not only associated with high adiposity, but also with hormonal disorder that compromises testosterone, estrogen, insulin, insulin-like growth factor (IGF)-1, and leptin, which have been linked to prostate cancer.

In vitro studies have demonstrated the mitogenic action of leptin in certain organs. Several isoforms of the leptin receptor have been reported in human tissues including the prostate and testes $[18,19]$. In this study, no diagnosis or follow-up of prostate cancer was performed as Canacci et al. [20], they studied the chemicals products in the male accessory glands and related them to the Gleason score [20]. Values of citric acid and other prostate products should be evaluated in later studies, especially in the more advanced stages of obesity.

Fructose levels were higher in II-III obesity, although in this study these patients were not categorized as diabetics, the relationship 
Citation: Lozano-Hernández R, Gualdrón J, Camejo MI, Velasco J, Villavicencio A (2017) Markers of accessory glands and seminal parameters in infertile men with overweight and obesity. J Metabolic Synd 6: 229. doi:10.4172/2167-0943.1000229

Page 4 of 4

between diabetes mellitus and obesity ratio in infertile men increases proportionally [21].

\begin{tabular}{|l|l|l|}
\hline \multirow{2}{*}{ Patients/Semen quality parameters } & \multicolumn{2}{|c|}{ BMI } \\
\cline { 2 - 3 } & $\mathbf{R}$ & p value \\
\hline Age (years) & 0.213 & 0.001 \\
\hline Semen Volume (mL) & -0.137 & 0.01 \\
\hline Spermatozoa (x106/ejaculate) & -0.158 & 0.01 \\
\hline Motility (\%) & -0.035 & Ns \\
\hline Normal morphology (\%) & -0.079 & Ns \\
\hline HOST (\%) & -0.065 & Ns \\
\hline PMN (mL) & 0.036 & Ns \\
\hline Fructose ( $\mu$ mol/ejaculate) & 0.149 & 0.01 \\
\hline Citric acid (mmol/ejaculate) & -0.279 & 0.001 \\
\hline Neutral alpha glucosidase (mUl/ejaculate) & -0.035 & Ns \\
\hline $\begin{array}{l}\text { Data was evaluated by Pearson correlation test; BMl: Body mass index; Ns: No } \\
\text { significant. }\end{array}$ & \multicolumn{2}{|l}{} \\
\hline
\end{tabular}

Table 3: Correlations between BMI and seminal parameters.

In seminal plasma of overweight and obese men adiponectin, progranulin and alpha-glucosidase levels are lower and fructose levels are higher than in men with normal weight. Fructose is a carbohydrate transported into sperm and is one of its main energy sources. Whether the high fructose levels in seminal plasma of obese males can explain the changes to sperm mitochondrial function remains to be determined [22].

\section{Conclusions}

The results indicate that obesity in a progressive and imperceptible way affects sperm and prostatic functions, although classic sperm parameters are mostly unchanged; oxidative stress, hormonal and metabolic changes are more severe as adiposity increases, so that infertility and prostate pathologies could be improved if hyperadiposity in infertile men is avoided opportunely.

\section{Acknowledgments}

We thank Mr. Héctor Picón for his technical work, Doctor Pedro Fernández, Doctor Henry Nava and Doctor Rubén Gallo for the clinical evaluation of the patients referred to the laboratory.

\section{References}

1. Pasquali R, Patton L, Gambineri A (2007) Obesity and infertility. Curr Opin Endocrinol Diabetes Obes 14: 482-487.

2. Hakonsen LB, Thulstrup AM, Aggerholm AS, Olsen J, Bonde JP, et al. (2011) Does weight loss improve semen quality and reproductive hormones? Results from a cohort of severely obese men. Reprod Health $8: 24$.
3. Ofei F (2005) Obesity - a preventable disease. Ghana Med J 39: 98-101.

4. Martini AC, Molina R, Ruiz RD, Fiol de Cuneo M (2012) Obesity and male fertility. Rev Fac Cien Med Univ Nac Cordoba 69: 102-110.

5. Palmer N, Bakos H, Fullston T, Lane M (2012) Impact of obesity on male fertility, sperm function and molecular composition. Spermatogenesis 2: 253-263.

6. Savini I, Catani MV, Evangelista D, Gasperi V, Avigliano L (2013) Obesity-associated oxidative stress: strategies finalized to improve redox state. Int J Mol Sci 14: 10497-10538.

7. Hoda MR, Theil G, Mohammed N, Fischer K, Fornara P (2012) The adipocyte-derived hormone leptin has proliferative actions on androgenresistant prostate cancer cells linking obesity to advanced stages of prostate cancer. J Oncol 280386.

8. Lotti F, Corona G, Colpi GM, Filimberti E, Degli Innocenti S, et al. (2011) Elevated body mass index correlates with higher seminal plasma interleukin 8 levels and ultrasonographic abnormalities of the prostate in men attending an andrology clinic for infertility. J Endocrinol Invest 34: $336-42$.

9. La Vignera S, Condorelli RA, Vicari E, Salmeri M, Morgia G, et al. (2014) Microbiological investigation in male infertility: a practical overview. J Med Microbiol 63: 1-14.

10. Lozano-Hernández R, Vivas-Acevedo G, Muñoz de Vera MG (2012) Mycoplasmas and antibodies anti-Chlamydia in semen of infertile men and their relationship with seminal quality and markers of male accessory sex glands. Invest Clin 53: 138-47.

11. Briceño E, Suárez E, Michelangi C, Feliciangeli D, Ptaiza E, et al. (2002) Mendible J. (eds) Código de Bioética y Bioseguridad, Ministerio de Ciencia y Tecnología (FONACIT). 2 (Edn), Venezuela.

12. http://www.who.int/reproductivehealth/publications/infertility/ 9789241547789/en

13. Lozano-Hernández R, Vivas-Acevedo G (2013) Análisis bioquímico del plasma seminal. En Cerezo G, Col Y (editors), Manual básico del semen. Ed Prado. México. pp: 81-97.

14. He Y, Pan A, Wang Y (2017) Prevalence of overweight and obesity in 15.8 million men aged 15-49 years in rural China from 2010 to 2014. Sci Rep 7:5012.

15. Pernenkil V, Wyatt T, Akinyemiju T (2017) Trends in smoking and obesity among US adults before, during, and after the great recession and Affordable Care Act roll-out. Prev Med 102: 86-92.

16. Taha EA, Sayed SK, Gaber HD, Abdel Hafez HK, Ghandour N, et al. (2016) Does being overweight affect seminal variables in fertile men? Reprod Biomed Online 33: 703-708.

17. Bernstein EF, Underhill CB, Lakkakorpi J, Ditre CM, Uitto J, et al. (1997) Citric acid increases viable epidermal thickness and glycosaminoglycan content of sun-damaged skin. Dermatol Surg 23: 689-694.

18. Stattin P, Söderberg S, Hallmans G, Bylund A, Kaaks R, et al. (2001) Leptin is associated with increased prostate cancer risk: a nested casereferent study. J Clin Endocrinol Metab 86: 1341-1345.

19. Noda T, Kikugawa T, Tanji N, Miura N, Asai S, et al. (2015) Longâ 'term $^{\prime}$ exposure to leptin enhances the growth of prostate cancer cells. Int J Oncol 46: 1535-1542.

20. Canacci AM, Izumi K, Zheng Y, Gordetsky J, Yao JL, eta 1. (2011) Expression of semenogelins I and II and its prognostic significance in human prostate cancer. Prostate 71: 1108-1114.

21. Bener A, Al-Ansari AA, Zirie M, Al-Hamaq AO (2009) Is male fertility associated with type 2 diabetes mellitus?. Int Urol Nephrol 41: 777-784.

22. McPherson NO, Lane M (2015) Male obesity and subfertility, is it really about increased adiposity?. Asian J Androl 17: 450-458. 